Editorial

\title{
Sediment source fingerprinting for informing catchment management: Methodological approaches, problems and uncertainty
}

The application of the sediment source fingerprinting approach has accelerated rapidly in recent years (Davis and Fox, 2009; Krishnappan et al., 2009; Mukundan et al., 2012; Walling, 2013; Gellis and Mukundan, 2013; Walling and Foster, 2016; Walling and Collins, 2016). One key driver for this increasing interest concerns the need to manage the excess fine (typically $<63 \mu \mathrm{m}$ fraction) sediment loads delivered to rivers worldwide and their associated detrimental impacts, including amongst others, those on water quality, treatability, and aquatic ecology (Gellis and Walling, 2011). The cost-effective targeting of management strategies requires reliable information on the key sources of the sediment problem at landscape or catchment scales, and sediment source tracing has the potential to avoid some of the logistical and cost constraints associated with traditional procedures for investigating erosion processes and subsequent sediment delivery to river channels.

Since the pioneering work of Klages and Hsieh (1975) and Wall and Wilding (1976), the number and diversity of studies applying sediment source fingerprinting has accelerated to the present, but therein, lies an urgent need for the scientific community to address the lack of standard procedures and protocols for the various key stages comprising the overall approach. From a conceptual stance, the fingerprinting approach is based on a small number of key assumptions, including: the key potential sources of sediment in any landscape or catchment can be readily identified for informing targeted sampling campaigns; representative source and sediment samples when compared using their properties (e.g. geochemistry, mineral-magnetism) or composite signatures (multiple individual properties; sensu Walling et al., 1993) provides a reliable basis for apportioning the key sources involved, and; tracer properties remain relatively conservative during transport from source to sink. Despite these underpinning elementary assumptions, much diversity has evolved in the procedures used to apply the general approach. Much of the current research and publications on sediment fingerprinting have objectives that include but are not limited to testing: (1) a growing number of different types of potential fingerprint properties, (2) contrasting approaches to classifying potential sediment source areas, (3) robust source discrimination using a growing variety of statistical tests (4) variations in numerical mixing model structures in response to issues associated with particle size and organic matter enrichment or depletion, (5) the direct comparability of source and sediment samples, and (6) the need to be explicit about the uncertainties associated with the source predictions. At the same time, studies applying the source fingerprinting approach have investigated the scope for sampling and sourcing a greater range of target sediment sample types, frequently driven by the need to help manage different environmental issues such as the siltation of salmonid spawning gravels (Walling et al., 2003) or the associated impacts of sedimentassociated organic matter (e.g. Collins et al., 2014), sedimentassociated nutrient transport (Walling et al., 2008) or the siltation of lakes, ponds or reservoirs (Foster et al., 2008).

In an attempt to address the current diversity in the methodological components of sediment source tracing procedures and the ongoing scientific debate over sampling methods, statistical analyses and treatment of uncertainty, a workshop was organized by the International Commission on Continental Erosion (ICCE) of the International Association of Hydrological Sciences (IAHS) at the 26th International Union of Geodesy and Geophysics (IUGG) meeting in 2015 in Prague to review methodological aspects of sediment fingerprinting. A key outcome arising from that workshop is the collection of papers herein.

Spatial variation in sediment source properties has been recognized as an important potential source of uncertainty for some time, but, to date, there have been few attempts to explore the nature and magnitude of such variability and its wider implications for source fingerprinting outputs. Given this important gap, the contribution from Du and Walling (2017) investigates this problem focusing on surficial sediment sources and associated geochemical properties within a single 7 ha cultivated field. Surface soil samples were retrieved from 52 points within the study field to explore the extent of the spatial variability of 53 geochemical properties. Particular attention is directed towards the importance of soil redistribution rates on the surface soil properties, guidelines for selecting sampling points and the degree of correlation between different soil properties and its implications for numerical data processing procedures.

The objective classification of sediment source groups also represents an under-investigated component of source tracing studies, yet has the potential to propagate uncertainty through tracer data processing procedures. Accordingly, the paper by Pulley et al. (2017) investigates three different source group classification schemes reflecting conventional surface and subsurface groupings, groups identified using a two-step cluster analysis, and a third scheme splitting each cluster-based grouping into a surface and subsurface component with the aim of assisting catchment management goals. The schemes were tested using artificial mixtures of sediment source samples. Overall, the paper demonstrates that cluster analysis based classification methods have the potential to 
reduce composite uncertainty significantly.

The third paper, by Manjoro et al. (2017) examines the potential uncertainties of using more than one sediment core collected from the same floodplain sink in a small catchment in the Eastern Cape, South Africa. The results show that the temporal patterns of sediment source contributions predicted for two sediment cores were very different despite the cores being collected in close proximity from the same floodplain. On this basis, discussion of the findings highlights some of the potential limitations associated with using floodplain cores to reconstruct catchment erosion processes and associated sediment source contributions.

The fourth contribution (Palazon and Navas, 2017) uses the $<63 \mu \mathrm{m}$ fraction of surface reservoir sediments (upper $2 \mathrm{~cm}$ ) to assess how the use of different statistical procedures impacts predicted source contributions. Three optimum composite fingerprints were selected to discriminate between the potential sediment sources using (1) discriminant function analysis, (2) the Kruskal-Wallis $\mathrm{H}$-test, and (3) principal component analysis. Predicted source contributions differed for each composite signature; however, a conceptual understanding of the study catchment suggested that the most reliable solutions were achieved using the Kruskal-Wallis $\mathrm{H}$-test combined with discriminant function analysis.

Moving on from the papers examining source or sink sampling, source group classification and statistical analyses, the next three contributions report different applications of the fingerprinting approach. The paper by Rowntree et al. (2017) uses low frequency magnetic susceptibility $\left(\mathrm{X}_{\mathrm{If}}\right)$, to apportion suspended sediment to geologically-defined source areas and to interpret sediment source changes during flood events in the degraded catchment of the Vuvu River, a headwater tributary of the Mzimbubu River, South Africa. Application of an un-mixing model with Monte Carlo uncertainty analysis showed that $\mathrm{X}_{\mathrm{If}}$ provided a means to assign the proportion of each geological source contributing to the sediment load. Sediment tracing using a single property $\left(\mathrm{X}_{\mathrm{If}}\right.$ was therefore used effectively to study changing sediment sources both between and during a flood event in a catchment with strongly contrasting magnetic signatures in different areas. Overall, the results support the use of magnetic susceptibility as a simple and inexpensive tool to determine sediment provenance. Nozrati (2017) applies radionuclide $\left({ }^{137} \mathrm{Cs},{ }^{40} \mathrm{~K},{ }^{238} \mathrm{U},{ }^{226} \mathrm{Ra},{ }^{232} \mathrm{Th}\right.$ ) tracers and soil organic carbon to determine the relative contributions of hillslope sediment sources (summit, shoulder, backslope, and toeslope) in two land use types in a mountainous catchment of western Iran using a Bayesian-mixing model. The results of the Bayesian mixing modelling, suggest that the highest contribution of sediment originates from cropped fields and shoulder-component landforms. The author argues that this approach has the potential to be useful for targeting soil erosion and sediment control strategies. Gellis et al. (2017) report the use fallout radionuclides ( $\mathrm{Be}$ and ${ }^{210} \mathrm{~Pb}_{\mathrm{ex}}$ ) sampled in bed sediment for 99 watersheds in the Midwestern region of the United States and in 15 samples of suspended sediment from 3 of these watersheds to partition upland from channel sources and to estimate the age or the time since the surface-derived portion of sediment was on the land surface ( $0-\sim 1$ year). Channel sources were found to dominate: 78 of the 99 bed material sites (79\%) had $>50 \%$ channel-derived sediment, and 9 of the 15 suspended sediment samples $(60 \%)$ had $>50 \%$ channel-derived sediment. The surface-derived portions of 54 of the 80 (68\%) streams with detectable ${ }^{7} \mathrm{Be}$ and ${ }^{210} \mathrm{~Pb}_{\mathrm{ex}}$ were $\leq 100$ days old and the surface-derived portions of all suspended-sediment samples were $\leq 100$ days old, indicating that surface-derived fine-grained sediment moves rapidly though these systems.

Finally, the paper by Collins et al. (2017) reviews several of the key challenges and uncertainties that continue to hamper consensus among the scientific community on key components of existing source tracing methodological procedures. Here, particular, attention is directed at sediment source classification, catchment source and target sediment sampling, tracer selection, grain size issues, tracer conservatism, source apportionment modelling, and assessment of source predictions using artificial mixtures. The paper ends with a new decision-tree representing the current state of knowledge, to guide end-users in applying the fingerprinting approach.

\section{References}

Collins, A.L., Williams, L.J., Zhang, Y.S., Marius, M., Dungait, J.A.J., Smallman, D.J., Dixon, E.R., Stringfellow, A., Sear, D.A., Jones, J.I., Naden, P.S., 2014. Sources of sediment-bound organic matter infiltrating spawning gravels during the incubation and emergence life stages of salmonids. Agric. Ecosyst. Environ. 196, 76-93.

Collins, A.L., Pulley, S., Foster, I.D.L., Gellis, A., Porto, P., Horowitz, A.J., 2017. Sediment source fingerprinting as an aid to catchment management: a review of the current state of knowledge and a methodological decision-tree for end-users. J. Environ. Manag. 194, 86-108.

Davis, C.M., Fox, J.F., 2009. Sediment fingerprinting: review of the method and future improvements for allocating nonpoint source pollution. J. Environ. Eng. ASCE 139, 490-504.

Du, P., Walling, D.E., 2017. Fingerprinting surficial sediment sources: exploring some potential problems associated with the spatial variability of source material properties. J. Environ. Manag. 194, 4-15.

Foster, I.D.L., Oldfield, F., Flower, R.J., Keatings, K., 2008. Trends in mineral magnetic signatures in a long core from Lake Qarun, Middle Egypt. J. Palaeolimnol. 40, 835-849.

Gellis, A.C., Mukundan, R., 2013. Watershed sediment source identification: tools, approaches and case studies. J. Soils Sediments 13, 1655-1657.

Gellis, A.C., Walling, D.E., 2011. Sediment source fingerprinting (tracing) and sediment budgets as tools in targeting river and watershed restoration programs. In: Simon, A., Bennett, S.J., Castro, J.M. (Eds.), Stream Restoration in Dynamic Fluvial Systems: Scientific Approaches, Analyses, and Tools. American Geophysical Union, pp. 263-291. Geophysical Monograph Series. 194.

Gellis, A.C., Fuller, C.C., Van Metre, P.C., 2017. Sources and ages of fine-grained sediment to streams using fallout radionuclides in the Midwestern United States. J. Environ. Manag. 194, 73-85.

Klages, M.G., Hsieh, Y.P., 1975. Suspended solids carried by the Gallatin River of Southwestern Montana: II. Using mineralogy for inferring sources. J. Environ. Qual. 4, 68-73.

Krishnappan, B.G., Chambers, P.A., Benoy, G., Culp, J., 2009. Sediment source identification: a review and a case study in some Canadian streams. Can. J. Civ. Eng. 36, 1622-1633.

Manjoro, M., Rowntree, K.M., Kakembo, V., Foster, I.D.L., Collins, A.L., 2017. Use of sediment source fingerprinting to assess the role of subsurface erosion in the supply of fine sediment in a degraded catchment in the Eastern Cape, South Africa. J. Environ. Manag. 194, 27-41.

Mukundan, R., Walling, D.E., Gellis, A.C., Slattery, M.C., Radcliffe, D.E., 2012. Sediment source fingerprinting: transforming from a research tool to a management tool. J. Am. Water Resour. Assoc. 48, 1241-1257.

Nozrati, K., 2017. Ascribing soil erosion of hillslope components to river sediment yield. J. Environ. Manag. 194, 63-72.

Palazon, L., Navas, A., 2017. Variability in source sediment contributions by applying different statistic test for a Pyrenean catchment. J. Environ. Manag. 194, 42-53.

Pulley, S., Foster, I.D.L., Collins, A.L., 2017. The impact of catchment source group classification on the accuracy of sediment fingerprinting outputs. J. Environ. Manag. 194, 16-26.

Rowntree, K.M., van der Waal, B.W., Pulley, S., 2017. Magnetic susceptibility as a simple tracer for fluvial sediment source ascription during storm events. J. Environ. Manag. 194, 54-62.

Wall, G.J., Wilding, L.P., 1976. Mineralogy and related parameters of fluvial suspended sediments in northwestern Ohio. J. Environ. Qual. 5, 168-173.

Walling, D.E., 2013. The evolution of sediment source fingerprinting investigations in fluvial systems. J. Soils Sediments 1310, 1658-1675.

Walling, D.E., Collins, A.L., 2016. Fine sediment transport and management. In: Gilvear, D.J., Greenwood, M.T., Thoms, M.C., Wood, P.J. (Eds.), River Science: Research and Management for the 21st Century. Wiley, London, pp. 37-60.

Walling, D.E., Foster, I.D.L., 2016. Using environmental radionuclides and sediment geochemistry for tracing and dating fine fluvial sediment. In: Mathias Kondolf, G., Piégay, Hervé (Eds.), Tools in Fluvial Geomorphology, second ed. Wiley, Chichester, pp. 183-209.

Walling, D.E., Woodward, J.C., Nicholas, A.P., 1993. A multi-parameter approach to fingerprinting suspended sediment sources. In: Peters, N.E., Hoehn, E., Leibundgut, Ch, Tase, N., Walling, D.E. (Eds.), Tracers in Hydrology. IAHS, Wallingford, pp. 329-338. IAHS Publication No. 215.

Walling, D.E., Collins, A.L., McMellin, G., 2003. A reconnaissance survey of the source of interstitial fine sediment recovered from salmonid spawning gravels in England and Wales. Hydrobiologia 497, 91-108.

Walling, D.E., Collins, A.L., Stroud, R., 2008. Tracing suspended sediment and particulate phosphorus sources in catchments. J. Hydrol. 350, 274-289. 
A.L. Collins*

Sustainable Soils and Grassland Systems Department, Rothamsted Research, Okehampton EX20 2SB, UK

I.D.L. Foster

Geography Department, Rhodes University, Grahamstown, 6140, South Africa

Faculty of Arts, Science \& Technology, University of Northampton, Northampton NN2 6JD, UK

A.C. Gellis

U.S. Geological Survey, Baltimore, MD 21228, USA Department of Agraria, University Mediterranea of Reggio Calabria, Italy

A.J. Horowitz ${ }^{1}$ U.S. Geological Survey, Atlanta, GA 30093, USA

${ }^{*}$ Corresponding author. 